\title{
Imaging and management of a small cell lung cancer metastasis/adrenal adenoma collision tumor: a case report and review of the literature
}

\author{
Brian R Untch ${ }^{*}$, Jinru Shia ${ }^{2}$, Robert J Downey ${ }^{1}$, Jorge A Carrasquillo ${ }^{3}$, David M Panicek ${ }^{3}$ and Vivian E Strong ${ }^{1}$
}

\begin{abstract}
Objective: We report a case of an adrenal collision tumor composed of a small cell lung carcinoma metastasis and a benign adrenal adenoma identified preoperatively on FDG-PET, CT and MRI and confirmed pathologically.

Methods: The patient's history, preoperative imaging characteristics, postoperative course, and histopathology are described. A review of the literature addressing adrenal collision tumors is provided.

Results: A 47-year-old female was found to have a left upper lobe lung mass and an adrenal lesion on imaging. FDG-PET, CT and MRI of the adrenal suggested a metastatic lesion adjacent to an adrenal adenoma. CT-guided biopsy of the adrenal gland was consistent with a small cell lung cancer metastasis. The patient underwent systemic chemotherapy and had complete resolution of the left upper lobe mass. Post-treatment FDG-PET demonstrated a persistently enlarged adrenal gland with decreased but persistent FDG uptake. The patient underwent adrenalectomy and pathologic examination demonstrated a small cell lung cancer/adenoma collision tumor.
\end{abstract}

Conclusions: This case and a review of the literature demonstrate that FDG, CT and MR imaging can all characterize the separate components of collision tumors within the adrenal gland.

Keywords: Collision tumor, Small cell lung cancer, Adrenal adenoma, Fluorodeoxyglucose positron emission tomography, Adrenal mass

\section{Background}

Composite tumors are those that have two different histologic types intermixed, whereas collision tumors are those in which two tumors abut each other or are in close proximity [1]. Collision tumors have been reported in nearly every organ in the body. They may be composed of two primary tumors from the same organ, or a primary tumor and a metastasis. The close approximation of two malignancies can create diagnostic and therapeutic dilemmas. If a mixed benign and malignant collision tumor is biopsied and only the benign component identified, sub-optimal treatment may be delivered.

Here we report an unusual case of a patient noted to have two left adrenal lesions on imaging, which were correctly characterized radiologically as a metastasis adjacent to a

\footnotetext{
* Correspondence: untchb@mskcc.org

'Department of Surgery, Memorial Sloan-Kettering Cancer Center, 1275 York Ave, New York, NY 10065, USA

Full list of author information is available at the end of the article
}

benign adrenal adenoma. This was confirmed by fine needle aspirate cytology and pathology after adrenalectomy. To our knowledge this is the first reported case of a small-cell lung carcinoma and adrenal adenoma collision tumor.

\section{Case presentation}

A 47-year-old woman developed cough and hoarseness that persisted after a course of antibiotics. A computed tomography $(\mathrm{CT})$ scan of the chest revealed a $6.0-\mathrm{cm}$ mass in the left upper lobe of the lung and bulky hilar adenopathy. In the left adrenal, two lesions were identified on non-contrast-enhanced images: a low-attenuation $2.9 \times 3.1-\mathrm{cm}$ lesion suggestive of a lipid-rich adenoma, and a higher attenuation $1.2 \times 1.4-\mathrm{cm}$ nodule suspicious for metastatic disease (Figure 1A). Fluorodeoxyglucose positron emission tomography (FDG-PET) confirmed that the low attenuation lesion of 5 Hounsfield units was not hypermetabolic. The standardized uptake value based

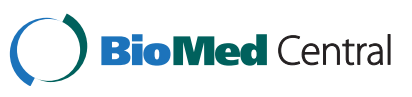



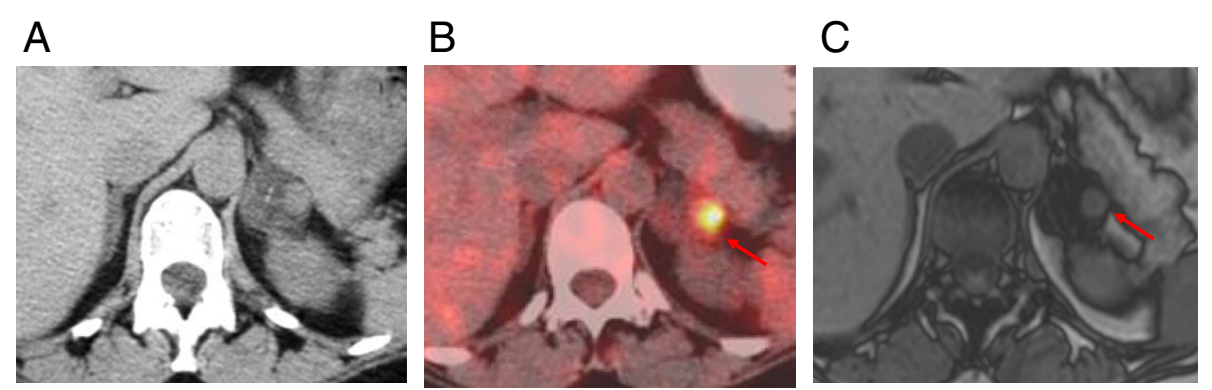

Figure 1 Pretreatment imaging of an adrenal collision tumor. (A) Non-contrast axial computed tomography scan (CT) demonstrating two distinct lesions in the left adrenal gland: a low attenuation $2.9 \times 3.1-\mathrm{cm}$ lesion as well as a higher attenuation $1.2 \times 1.4-\mathrm{cm}$ nodule, suspicious for metastatic disease. (B) Fused CT/fluorodeoxyglucose (FDG) positron emission tomography scan demonstrates an FDG avid lesion in the high attenuation component (standardized uptake value (SUVmax) 7) and no significant uptake in the low attenuation component. (C) Opposed-phase axial magnetic resonance imaging shows loss of signal intensity in the majority of the left adrenal mass, consistent with a lipid-rich adrenal adenoma, largely surrounding a 1.2-cm mass within the lateral portion of the adrenal gland that did not lose signal intensity, suggestive of metastatic disease.

on body weight (SUVmax) was 1.8, consistent with an adenoma. The smaller, higher attenuation lesion (31 Hounsfield units) within the adrenal was hypermetabolic (SUVmax 7) consistent with metastatic disease (Figure 1B). At chemical-shift magnetic resonance imaging (MRI), two distinctly different components were demonstrated, also suggestive of a collision tumor (Figure 1C). A percutaneous CT-guided biopsy of the adrenal tumor revealed malignant cells consistent with small-cell lung cancer. After treatment with six courses of etoposide and cisplatin, her CT scan showed a marked decrease in the size of the lung tumor as well as near complete resolution of the associated lymphadenopathy. However, the left adrenal remained persistently enlarged on $\mathrm{CT}$, despite a decrease in FDG avidity on PET imaging (SUVmax decreased from 7.0 to 2.7). Given the patient's age and response to chemotherapy, adrenalectomy was recommended to determine the presence of persistent disease after chemotherapy, and possibly to render the patient free of metastases. Lung resection was not thought to be beneficial because of the tumor response noted on imaging. The patient underwent an uncomplicated laparoscopic left adrenalectomy. Pathologic examination of the adrenal revealed a small-cell lung carcinoma metastasis adjacent to an adrenal adenoma. Nuclear thyroid transcription factor-1 (TTF-1) and cytoplasmic chromogranin immunohistochemical staining were positive in the small-cell carcinoma component, but not in the adrenal adenoma (Figure 2). Postoperatively the patient underwent a further three months of chemotherapy.

The patient remained free of disease for 1 year, but was then found to have pancreatic metastases. She died 4 months later, approximately two years after her original diagnosis.

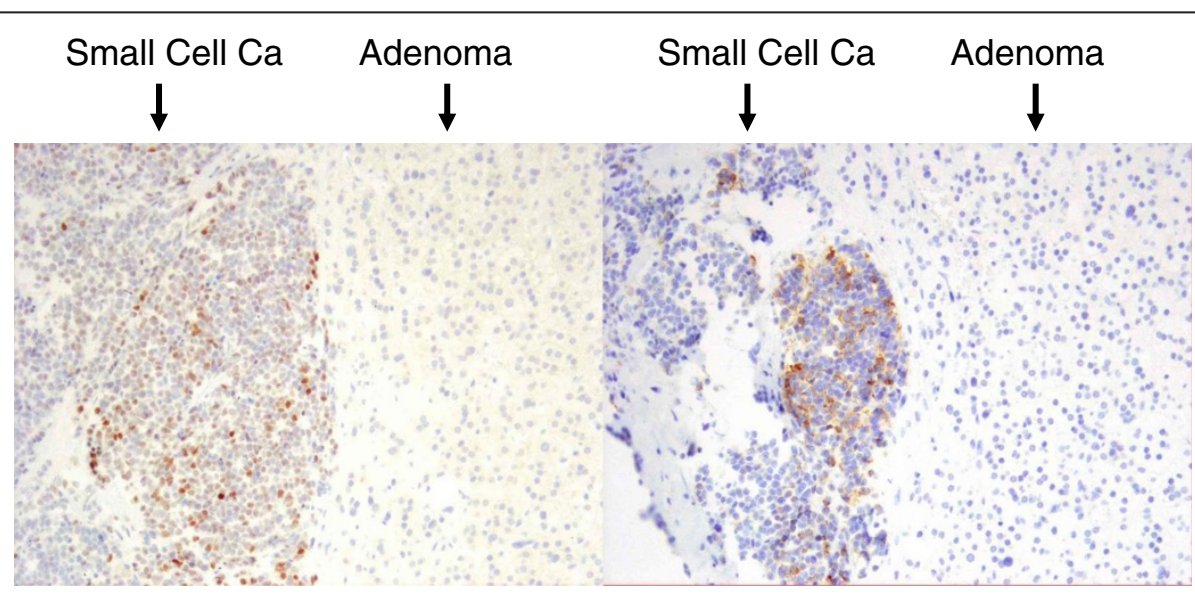

Nuclear TTF-1

\section{Cytoplasmic Chromogranin}

Figure 2 Immunohistochemistry of resected collision tumor. Nuclear thyroid transcription factor-1 (TTF-1) immunohistochemical staining (left) and cytoplasmic chromogranin staining (right) were positive in the small cell carcinoma component, but not in the adrenal adenoma. 


\section{Conclusions}

The reason why collision tumors develop is unclear. Malignancies have been found to promote local and distant sites of disease, and it is plausible that these same factors could facilitate the growth of second primary tumors. The initial tumor may create a milieu that makes it easier for a second tumor to grow [2,3]; in vitro and clinical evidence suggests that peri-tumoral tissue can facilitate the growth of tumor cells in and around the primary tumor via paracrine signaling $[4,5]$. Primary tumors are capable of secreting circulating growth factors that can facilitate metastatic spread and subsequent metastatic tumor growth [6]. Also playing a role may be bone marrowderived cells which, when recruited to tumor sites, can facilitate growth of the primary tumor and metastases [7].

Collision tumors are rare in the adrenal gland at imaging, occurring in 2 out of 104 patients MRI in a study by Schwartz et al. [2]. Case reports of biopsy-proven adrenal collision tumors in the literature are summarized in Table 1. In all cases, primary adrenal tumors were one component of the collision tumor [2,8-13]. In 9 of 11 patients, the second tumor was a metastasis. Identification of the tumors by imaging was successful in all but one case [8]. This case was a large heterogeneous tumor that was composed of a rectal cancer metastasis and an adrenal carcinosarcoma. Otherwise, CT and MRI were able to successfully demonstrate that two different tumor types were present in the same adrenal gland. In this case the successful imaging identification of a collision tumor led to appropriate biopsy of a metastasis and subsequent systemic therapy.

Various radiologic techniques are available for characterization of adrenal masses discovered incidentally during imaging performed for other purposes [14].
Approximately 7 to $10 \%$ of such masses represent adrenal adenomas, which can be identified on non-contrast CT if their attenuation measures less than 10 Hounsfield units, or by the more sensitive quantitative changes in enhancement values obtained at baseline and at 15-minute washout CT. Alternatively, chemical-shift imaging can identify about $70 \%$ of adrenal adenomas as such, based on their high lipid content. On opposed-phase images, the signal intensities of the intermixed lipid and water components present within an adenoma will cancel each other, resulting in signal loss in those locations relative to the in-phase images. At PET scanning, adrenal adenomas generally show low FDG avidity. In retrospect, the patient in this case report could have been managed with a combined PET/CT alone as this also allows for interval evaluation of the tumor metabolic activity after systemic therapy.

The decision to pursue adrenalectomy for this patient was based on the patient's age, the excellent treatment response, and the persistent adrenal lesion noted on CT that had a discordant FDG-PET response compared to the primary site of disease. Additionally, the literature supports the possible benefit of resection of a solitary site of hematogenous metastasis in non-small-cell lung cancer [15]. The efficacy and safety of laproscopic adrenalectomy has made metastasectomy a favored approach for patients with isolated metastatic disease. The laparoscopic approach is associated with shorter hospital stay, lower blood loss and lower morbidity $[16,17]$ This, combined with the five-year survival data ranging from 24 to $31 \%$, depending on the tumor type, makes the treatment approach reasonable in select patients $[18,19]$.

In summary, we report the first case in the literature of an adenoma-small-cell lung cancer collision tumor in

Table 1 Published reports of biopsy-proven adrenal collision/composite tumors

\begin{tabular}{|c|c|c|c|c|c|}
\hline Author & $\begin{array}{l}\text { Histology of } \\
\text { first tumor }\end{array}$ & $\begin{array}{l}\text { Histology of } \\
\text { second tumor }\end{array}$ & $\begin{array}{l}\text { Imaging } \\
\text { modality }\end{array}$ & Imaging results & $\begin{array}{l}\text { Lesion } \\
\text { size }\end{array}$ \\
\hline Bertolini et al. [8] & Adrenal carcinosarcoma & Rectal cancer & CT/MRI & One heterogeneous tumor & $14 \mathrm{~cm}$ \\
\hline Thorin-Savoure et al. [9] & Adrenal adenoma & Sigmoid cancer & CT & Two components of different attenuation & $3 \mathrm{~cm}$ \\
\hline Thorin-Savoure et al. [9] & Adrenal adenoma & Breast cancer & CT & Two components of different attenuation & $4.1 \mathrm{~cm}$ \\
\hline Hagspiel [10] & Adrenal myelolipoma* & Hodgkin's lymphoma* & CT & Two components of different attenuation & 1.2. $\mathrm{cm}$ \\
\hline Blake et al. [11] & Adrenal adenoma & $\begin{array}{l}\text { Spermatic cord } \\
\text { leiomyoscarcoma }\end{array}$ & $\mathrm{PET} / \mathrm{CT}$ & $\begin{array}{l}\text { Two components of different attenuation } \\
\text { and metabolic activity }\end{array}$ & $2.5 \mathrm{~cm}$ \\
\hline Otal et al. [12] & Adrenal adenoma & Adrenal myelolipoma & $\mathrm{CT} / \mathrm{MRI}$ & $\begin{array}{l}\text { Two components of different attenuation } \\
\text { and signal intensity }\end{array}$ & NA \\
\hline Otal et al. [12] & Adrenal adenoma & Adrenal myelolipoma & CT & Two components of different attenuation & NA \\
\hline Schwartz et al. [2] & Adrenal adenoma & Non-small cell lung cancer & MRI & Two components of different signal intensity & NA \\
\hline Schwartz et al. [2] & Adrenal adenoma & Breast cancer & MRI & Two components of different signal intensity & NA \\
\hline Hoshi et al. [13] & Adrenal adenoma* & Non-small-cell lung cancer* & CT & Two components of different attenuation & NA \\
\hline $\begin{array}{l}\text { Untch et al. } \\
\text { (Current study) }\end{array}$ & Adrenal adenoma & Small-cell lung cancer & $\mathrm{CT} / \mathrm{PET} / \mathrm{MRI}$ & $\begin{array}{l}\text { Two components of different attenuation, } \\
\text { signal intensity, and metabolic activity }\end{array}$ & $2.5 \mathrm{~cm}$ \\
\hline
\end{tabular}

*Histology confirmed at autopsy. CT, computed tomography; MRI, magnetic resonance imaging; PET, positron emission tomography; NA - not available. 
the adrenal gland. This case and the literature review demonstrate that FDG-PET, CT and MRI can all distinguish two separate components of collision tumors within the adrenal gland and, in the case of adrenal adenoma, provide a definitive diagnosis for that component. When a satisfactory post-treatment evaluation of such lesions is not possible with these imaging modalities, surgical intervention in select patients should be considered.

\section{Consent}

Written informed consent was obtained from the patient for publication of this Case report and any accompanying images. A copy of the written consent is available for review by the Editor-in-Chief of this journal.

\section{Abbreviations}

CT: Computed tomography; MRI: Magnetic resonance imaging;

FDG-PET: Fluorodeoxyglucose positron emission tomography:

SUV: Standardized uptake value; TTF-1: Thyroid transcription factor-1.

\section{Competing interests}

The authors declare that they have no competing interests.

\section{Authors' contributions}

BRU performed the literature review, and designed and drafted the manuscript. JS, RJD, JAC, and DMP assisted in drafting the manuscript and designing the figures. VES conceived the study and assisted in drafting the manuscript. All authors read and approved the final manuscript.

\section{Author details}

'Department of Surgery, Memorial Sloan-Kettering Cancer Center, 1275 York Ave, New York, NY 10065, USA. ²Department of Pathology, Memorial Sloan-Kettering Cancer Center, New York, NY, USA. ${ }^{3}$ Department of Radiology, Memorial Sloan-Kettering Cancer Center, New York, NY, USA.

Received: 4 February 2013 Accepted: 10 February 2014

Published: 26 February 2014

\section{References}

1. Meyer R: Beitrag zur Verstandigung uber die Namengebung in der Geschwaltstlehre [Article in German]. Zentralbl Allgm pathol 1919, 30:291-296

2. Schwartz LH, Macari M, Huvos AG, Panicek DM: Collision tumors of the adrenal gland: demonstration and characterization at MR Imaging. Radiology 1996, 201:757-760.

3. Sarbia M, Katoh E, Borchard F: Collision tumor of squamous cell carcinoma and leiomyoma in the esophagus. Pathol Res Pract 1993, 189:360-362.

4. Fridman WH, Galon J, Pages F, Tartour E, Sautes-Fridman C, Kroemer G Prognostic and predictive impact of intra- and peritumoral immune infiltrates. Cancer Res 2011, 71:5601-5605.

5. Wyckoff J, Wang W, Lin EY, Wang Y, Pixley F, Stanley ER, Graf T, Pollard JW, Segall J, Condeelis J: A paracrine loop between tumor cells and macrophages is required for tumor cell migration in mammary tumors. Cancer Res 2004, 64:7022-7029.

6. Hiratsuka S, Watanabe A, Aburantani H, Maru Y: Tumour-mediated upregulation of chemoattractants and recruitment of myeloid cells predetermines lung metastasis. Nat Cell Biol 2006, 8:1369-1375.

7. Kaplan RN, Riba RD, Zacharoulis S, Bramley AH, Vincent L, Costa C, MacDonald DD, Jin DK, Shido K, Kerns SA, Zhu Z, Hicklin D, Wu Y, Port JL, Altorki N, Port ER, Ruggero D, Shmelkov SV, Jensen KK, Rafii S, Lyden D: VEGFR1-positive haematopoietic bone marrow progenitors initiate the pre-metastatic niche. Nature 2005, 438:820-827.

8. Bertolini F, Rossi G, Fiochhi F, Giacometti M, Fontana A, Gibertini MC, Roncucci L, Luppi G, Torricelli P, Rossi A, Conte PF: Primary adrenal gland carcinosarcoma associated with metastatic rectal cancer: a hitherto unreported collision tumor. Tumori 2011, 97:27e-30e.
9. Thorin-Savoure A, Tissier-Rible F, Guignat L, Pellerin A, Bertagna X, Bertherat J, Lefebvre $\mathrm{H}$ : Collision/composite tumors of the adrenal gland: A pitfall of scintigraphy imaging and hormone assays in the detection of adrenal metastasis. J Clin Endo Metabol 2005, 90:4924-4929.

10. Hagspeil KD: Manifestation of Hodgkin's lymphoma in an adrenal myelolipoma. Eur Radiol 2005, 15:1757-1759.

11. Blake MA, Sweeney AT, Kalra MK, Maher MM: Collision adrenal tumors on PET/CT. AJR Am J Roentgenol 2004, 183:864-865.

12. Otal P, Escourrou G, Mazerolles C, Janne d'Othee B, Mezghani S, Musso S, Colombier D, Rousseau $\mathrm{H}$, Joffre F: Imaging features of uncommon adrenal masses with histopathologic correlation. Radiographics 1999, 19:569-581.

13. Hoshi H, Jinnouchi S, Ono S, Kihara Y, Arakawa K, Takeuchi M, Watanabe K: Scintigraphic demonstration of coexisting adenoma dn metastasis of the adrenal gland in a patient with bronchogenic carcinoma. Clin Nucl Med 1984, 9:717-718.

14. Boland GW, Blake MA, Hahn PF, Mayo-Smith WW: Incidental Adrenal Lesions: Principles, techniques, and algorithms for imaging characterization. Radiology 2006, 249:756-775.

15. Tanvetyanon T, Robinson LA, Schell MJ, Strong VE, Kapoor R, Coit DG, Belper G: Outcomes of adrenalectomy for isolated synchronous versus metachronous adrenal metastases in anon-small-cell lung cancer: a systematic review and pooled analysis. J Clin Oncol 2008, 26:1142-1147.

16. Kebebew E, Siperstein AE, Clark OH, Duh QY: Results of laparoscopic adrenalectomy for suspected and unsuspected malignant adrenal neoplasms. Arch Surg 2002, 137:948-951.

17. Strong VE, D'Angelica M, Tang L, Prete F, Gonen M, Coit D, Touijer KA, Fong $Y$, Brennan MF: Laparoscopic adrenalectomy for isolated adrenal metastasis. Ann Surg Oncol 2007, 14:3392-3400.

18. Kim SH, Brennan MF, Russo P, Burt ME, Coit DG: The role of surgery in the treatment of clinically isolated adrenal metastasis. Cancer 1998, 82:389-394.

19. Sarela Al, Murphy I, Coit DG, Conlon KC: Metastasis to the adrenal gland: the emerging role of laparoscopic surgery. Ann Surg Oncol 2003, 10:1191-1196

doi:10.1186/1477-7819-12-45

Cite this article as: Untch et al:: Imaging and management of a small cell lung cancer metastasis/adrenal adenoma collision tumor: a case report and review of the literature. World Journal of Surgical Oncology 2014 12:45.

\section{Submit your next manuscript to BioMed Central and take full advantage of:}

- Convenient online submission

- Thorough peer review

- No space constraints or color figure charges

- Immediate publication on acceptance

- Inclusion in PubMed, CAS, Scopus and Google Scholar

- Research which is freely available for redistribution 